\title{
NOTES FROM AN ADJUNCT PROFESSOR AT A MAJOR AMERICAN UNIVERSITY:
}

You make a cross of split forks and cedar and hang it on the wall to protect me while I teach. When I ask

what you are afraid of, you remove a list from the inside pocket of your purse and begin to read with admittedly great

thunder and silence-pregnancy pacts, you say; boys with white hands following you home; ball gags;

panic in a crowd; wet boots; that they'll

find out you're Jewish; the Internet; glycerin soap; rap music; halter tops; the oversexualization of aging men in positions of influence; what they will offer

in your office; what you will offer in your office; their age; your immaturity; a natural disaster in which you give your lunch to a group

of college freshman so they can survive an extra 48 hours and you die a slow, emaciating death; a car wreck; leaving town; how many of them admit to anal sex; beaches; insurance; rainwater; birthmarks; and pregnancy 
pacts. I never ask you about the repetition, but you confess, later at

an Italian restaurant, that the most frightening thing, the most terrifying thing, the thing that keeps you from leaving the house when I invite you to magic shows, is that somewhere

along the line you've agreed to carry an unspecified man's baby. You say you know the call is coming. That you can't back out. That you are sure when I see you

sick in the mornings I will take the dog and the Chrysler and leave after speaking very authoritatively on the nature of fidelity. But how would I know it isn't

mine? I ask, rubbing my palms against the raise of my wallet. That's why I made you this cross, you say. When it happens, I pray my uterus just collapses. 